\title{
Effects of topical indomethacin pretreatment on argon laser trabeculoplasty: a randomised, double-masked study on black South Africans
}

\author{
YUVAL A GELFAND AND MAUREEN WOLPERT \\ From the Department of Ophthalmology, University of the Witwatersrand, Johannesburg, and St John's Eye \\ Unit, Baragwanath Hospital, Soweto, South Africa
}

SUMmary This randomised, double-masked study on 45 black South Africans compares the effect of topical indomethacin pretreatment with that of placebo on the immediate postoperative increase or reduction in intraocular pressure one week and one month after argon laser trabeculoplasty. There was no significant difference in the incidence and the magnitude of the immediate postoperative intraocular pressure increase between the two groups, though they occurred significantly later in the indomethacin-treated group $(\mathrm{p}<0 \cdot 01)$. Although no effect of indomethacin pretreatment on the intraocular pressure reduction was evident after one week, a significant adverse effect of the drug was demonstrated after one month $(\mathrm{p}<0 \cdot 01)$.

Since its introduction argon laser trabeculoplasty' has proved very successful in the treatment of open angle glaucoma. ${ }^{2-6}$ It is indicated for patients whose intraocular pressures are not controlled on the maximum tolerated medical therapy.

The early complications of the procedure are well known. ${ }^{78}$ Two of these are of great concern. The first is immediate postoperative intraocular pressure increase, which can lead to rapid visual field loss. The second is postoperative intraocular inflammation, which can possibly contribute to the immediate postoperative intraocular pressure increase and affect the long-term control of the glaucoma. A number of techniques have been tried in an attempt to overcome these problems. It has been found that argon laser trabeculoplasty, when applied to only one half $\left(180^{\circ}\right)$, rather than the whole circumference $\left(360^{\circ}\right)$ of the trabecular meshwork, can decrease the magnitude, but not the incidence, of the immediate postoperative intraocular pressure increase." Corticosteroid pretreatment on the other hand does not influence either the immediate postoperative intraocular pressure increase or the intraocular pressure two months later."'

We conducted a randomised double-masked study using $1 \%$ indomethacin in aqueous suspension prior

Correspondence to Dr Y A Gelfand, Department of Ophthalmology, Medical School, York Road, Parktown, Johannesburg, South Africa 2193. to argon laser trabeculoplasty to check the influence of this drug on the incidence and the magnitude of the immediate postoperative intraocular pressure increase as well as the intraocular pressure one week and one month after the operation. To our knowledge this is the first study to analyse the effect of topical indomethacin pretreatment on the intraocular pressures following argon laser trabeculoplasty.

\section{Subjects and methods}

Forty-five consecutive South African black patients for whom argon laser trabeculoplasty was indicated were included in this randomised, double-masked study conducted from August 1983 to May 1984. The study was approved by the Ethics Committee of Baragwanath Hospital, Soweto, South Africa, and all patients gave their formal consent. Each patient received treatment in one eye only. All had openangle glaucoma, with intraocular pressures inadequately controlled by the maximum tolerated medication. The following patients were excluded from the study: those with only one eye; those under the age of 40; those who within the previous four months had undergone intraocular surgery in the eye to be treated; those in whom there was poor visibility of the trabecular meshwork due to an extremely narrow angle, corneal oedema, etc.; those with anterior uveitis; those who had previously received argon 
laser trabeculoplasty to one half of the angle in the eye to be treated; and those who were unable to cooperate at the slit lamp.

Two sets of identical bottles, one containing $5 \mathrm{ml}$ of $1 \%$ indomethacin ophthalmic suspension in aqueous solution and one containing $5 \mathrm{ml}$ of placebo, were supplied by MSD (Merck Sharp and Dohme International, South Africa). These bottles had previously been randomised and then labelled with consecutive numbers, in which sequence they were given to consecutive patients. The code was kept by one of us (MW), who was not directly involved in the study. One drop of indomethacin ophthalmic suspension (or placebo) was administered by a nursing sister to the eye to be treated at 2 hours, 1.5 hours, 1 hour, and 0.5 hour prior to the operation.

Argon laser trabeculoplasty was performed by one of us (YAG) between 9 am and $10.30 \mathrm{am}$, using the following technique. The eye to be treated was anaesthetised with one drop of $0 \cdot 4 \%$ oxybuprocaine (Novesin). A three-mirrored Goldmann gonioscopy lens was placed on the eye. Fifty equally spaced burns over $180^{\circ}$ were applied to the anterior part of the trabecular meshwork. The following laser setting was used: $800 \mathrm{~mW}$ for a duration of $0 \cdot 1$ second and a spot size of $50 \mu \mathrm{m}$.

The intraocular pressures of both the treated and untreated eyes were determined with a Goldmann applanation tonometer by one of us (YAG) at the following times: one hour preoperation; every hour postoperation for five hours (i.e., the immediate postoperative period); one week and one month postoperation (i.e., the early postoperative period). All preoperative glaucoma medications were continued during the postoperative period, but no additional medications (e.g., topical steroids or indomethacin) were given.

Corrected intraocular pressure changes were calculated for all times by subtracting the change in the intraocular pressure of the untreated eye from that of the treated eye. For the immediate postoperative period the maximum corrected increase in the postoperative intraocular pressure, as well as the hour at which it occurred, was noted. The intraocular pressures for each eye in the early postoperative period and before treatment of the same eye were compared. Pressure change of the untreated eye was then subtracted from the intraocular pressure change of the treated eye. By this method, which uses the untreated eyes as controls, one can eliminate bias caused by diurnal intraocular pressure variations, random fluctuations, and the patient's compliance with medical treatment. ${ }^{9}$ Patients for whom data were not available after one week (one patient in the indomethacin-treated group, two in the placebotreated group) and one month (three patients in the
Table 1 Summary of patients' data

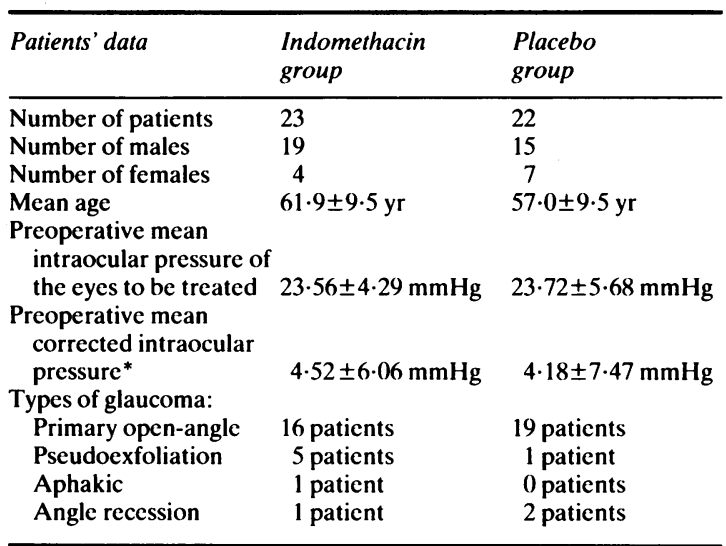

*This value was calculated by subtracting the intraocular pressure of the untreated eye from that of the cyc to be treated.

indomethacin-treated group, five in the placebotreated group) did not return for follow-up.

Patients' data are summarised in Table 1. There were 23 patients in the indomethacin-treated group (19 males, 4 females) with an average age of $61.9 \pm 9.5$ years. In the placebo-treated group there were 22 patients ( 15 males, 7 females) with an average age of $57.0 \pm 9.5$ years. Each patient received treatment in one eye only. Student's $t$ test was used for all statistical comparisons between the two groups.

Prior to treatment the mean intraocular pressure of the eyes to be treated was $23.56 \pm 4.29 \mathrm{mmHg}$ in the indomethacin-treated group and $23 \cdot 72 \pm 5.68 \mathrm{mmHg}$ in the placebo-treated group, there being no statistically significant difference between the two. Furthermore, there was no statistically significant difference between the mean corrected intraocular pressures of these two groups preoperatively; they were $4.52 \pm$ $6.06 \mathrm{mmHg}$ in the indomethacin-treated group and $4 \cdot 18 \pm 7.47 \mathrm{mmHg}$ in the placebo-treated group.

\section{Results}

Table 2 summarises the maximum corrected intraocular pressure change during the first five hours for the indomethacin-treated group and the placebotreated group. It also shows the hour at which this occurred. The mean maximum corrected intraocular pressure increase of the indomethacin-treated group was $1.39 \pm 4.18 \mathrm{mmHg}$ and that of the placebotreated group $1.63 \pm 5.8 \mathrm{mmHg}$. There was no statistically significant difference between the two groups. Furthermore, there was found to be no difference in the incidence of the intraocular pressure elevation between the two groups. In both groups 13 patients had raised intraocular pressures, two showed no 
Table 2 Maximum corrected intraocular pressure change during the first five hours after operation, and the hour at which it occurred

\begin{tabular}{|c|c|c|c|c|c|}
\hline \multicolumn{3}{|c|}{ Indomethacin group } & \multicolumn{3}{|c|}{ Placebo group } \\
\hline $\begin{array}{l}\text { Patient } \\
\text { no. }\end{array}$ & $\begin{array}{l}\text { Corrected } \\
\text { pressure } \\
\text { change } \\
(\mathrm{mmHg})\end{array}$ & Hour & $\begin{array}{l}\text { Patient } \\
\text { no. }\end{array}$ & $\begin{array}{l}\text { Corrected } \\
\text { pressure } \\
\text { change } \\
(\mathrm{mmHg})\end{array}$ & Hour \\
\hline 1 & +2 & 5 & 2 & -1 & 1 \\
\hline 3 & -1 & 5 & 4 & -3 & 1 \\
\hline 7 & +4 & 3 & 5 & +3 & 2 \\
\hline 8 & +1 & 1 & 6 & -3 & 1 \\
\hline 10 & +9 & 3 & 9 & -6 & 4 \\
\hline 11 & +5 & 2 & 12 & +1 & 1 \\
\hline 15 & +1 & 1 & 13 & 0 & 4 \\
\hline 16. & +4 & 1 & 14 & +5 & 3 \\
\hline 18 & 0 & 1 & 17 & -5 & 1 \\
\hline 20 & +2 & 1 & 19 & +2 & 1 \\
\hline 22 & -3 & 1 & 21 & +10 & 1 \\
\hline 24 & -4 & 3 & 23 & +3 & 1 \\
\hline 25 & -5 & 3 & 26 & +12 & 1 \\
\hline 27 & +4 & 2 & 28 & +4 & 1 \\
\hline 29 & +2 & 2 & 30 & 0 & 1 \\
\hline 32 & -1 & 2 & 31 & +8 & 2 \\
\hline 35 & 0 & 2 & 33 & +1 & 1 \\
\hline 36 & +8 & 4 & 34 & +6 & 2 \\
\hline 37 & -2 & 1 & 39 & +3 & 2 \\
\hline 38 & +1 & 4 & 40 & -13 & 1 \\
\hline 43 & -4 & 1 & 41 & +10 & 1 \\
\hline 44 & -2 & 3 & 42 & -1 & 1 \\
\hline 45 & +11 & 3 & & & \\
\hline
\end{tabular}

Table 3 Corrected intraocular pressure changes after one week and one month

\begin{tabular}{|c|c|c|c|c|c|}
\hline \multicolumn{3}{|c|}{ Indomethacin group $(\mathrm{mmHg})$} & \multicolumn{3}{|c|}{ Placebo group $(\mathrm{mmHg})$} \\
\hline $\begin{array}{l}\text { Patient } \\
\text { no. }\end{array}$ & One week & $\begin{array}{l}\text { One } \\
\text { month }\end{array}$ & $\begin{array}{l}\text { Patient } \\
\text { no. }\end{array}$ & One week & $\begin{array}{l}\text { One } \\
\text { month }\end{array}$ \\
\hline 1 & -2 & -4 & 2 & -6 & -11 \\
\hline 3 & -2 & -1 & 4 & - & - \\
\hline 7 & -5 & -5 & 5 & -4 & -5 \\
\hline 8 & -2 & +2 & 6 & -10 & -5 \\
\hline 10 & 0 & -2 & 9 & - & - \\
\hline 11 & +1 & -7 & 12 & -4 & -2 \\
\hline 15 & -3 & -7 & 13 & -4 & -6 \\
\hline 16 & +3 & -3 & 14 & -1 & -5 \\
\hline 18 & 0 & 0 & 17 & -8 & -8 \\
\hline 20 & -8 & -8 & 19 & -4 & -4 \\
\hline 22 & -10 & -4 & 21 & -10 & - \\
\hline 24 & -10 & -8 & 23 & -2 & -8 \\
\hline 25 & -7 & -8 & 26 & -6 & -4 \\
\hline 27 & -2 & 0 & 28 & -2 & -4 \\
\hline 29 & - & -5 & 30 & -5 & -3 \\
\hline 32 & -3 & - & 31 & +2 & -6 \\
\hline 35 & -5 & -7 & 33 & +1 & -7 \\
\hline 36 & -4 & +4 & 34 & -5 & -4 \\
\hline 37 & -5 & -1 & 39 & 0 & -6 \\
\hline 38 & -15 & - & 40 & -10 & - \\
\hline 43 & -12 & -8 & 41 & -3 & - \\
\hline 44 & -8 & - & 42 & -4 & -7 \\
\hline 45 & +7 & -1 & & & \\
\hline
\end{tabular}

change, while eight patients in the indomethacintreated group and seven in the placebo-treated group showed decreased intraocular pressures. On the other hand a statistically significant difference was found between the average times at which the maximum increase in the intraocular pressures occurred. In the indomethacin-treated group the average time for the maximum intraocular pressure increase was $2.34 \pm 1.30$ hours and in the placebotreated group $1.54 \pm 0.96$ hours $(\mathrm{p}<0.01)$.

Table 3 shows the corrected changes in the intraocular pressures after one week and one month for the indomethacin-treated group and the placebotreated group. After one week the mean corrected intraocular pressure of the indomethacin-treated group was $-4.18 \pm 5.09 \mathrm{mmHg}$, and that of the placebo-treated group $-4.25 \pm 3.46 \mathrm{mmHg}$. This difference is not statistically significant. After one month, however, the mean corrected intraocular pressure of the indomethacin-treated group was $-3.65 \pm 3.66 \mathrm{mmHg}$ and of the placebo-treated group $-5 \cdot 59 \pm 2 \cdot 18 \mathrm{mmHg}$. This difference is statistically significant $(p<0 \cdot 01)$.

\section{Discussion}

The basis for the immediate postoperative intraocular pressure increase, which is often seen after argon laser trabeculoplasty, is not known, nor are the factors which contribute to the failure of the procedure. However, electron microscopic studies of preparations of the trabecular meshwork which were obtained immediately after argon laser trabeculoplasty showed shrinkage of the collagen fibres of the trabecular beams, accompanied by oedema and inflammation." It is possible, therefore, that both inflammation (even if subclinical) and mechanical factors contribute to the immediate increase in the intraocular pressure following the operation. The presence of inflammation is not surprising in view of the fact that the burns are applied very close to the ciliary body and the iris root, which are one of the main sources of prostaglandin production in the eye. ${ }^{12}$ The application of argon laser burns to the iris has long been known to be a cause of prostaglandinmediated breakdown of the blood-aqueous barrier, which can be blocked partially by pretreatment with indomethacin. ${ }^{1213}$ Indomethacin is known to inhibit the synthesis of prostaglandins, but the drug cannot antagonise their effects once they have been formed. ${ }^{14}$ It seems logical, therefore, to treat preoperatively with indomethacin so that the intraocular concentration of the drug will reach peak levels at the time of the operation, when synthesis of prostaglandins is likely to occur.

In our study we applied topical indomethacin at 
half-hourly intervals, starting from two hours prior to the operation. This method of application is very similar to that used in the pioneering studies in Japan, ${ }^{15} 16$ in which topical indomethacin pretreatment was shown to suppress postoperative inflammation following cataract surgery in human eyes. In our study, however, we doubled the concentration of indomethacin, and used $1 \%$ rather than $0.5 \%$. We are not aware of any studies which measure the penetration of topical indomethacin ophthalmic suspension in the human eye. In rabbits, however, ${ }^{17}{ }^{18}$ the drug was found to penetrate the cornea quickly, with a peak concentration of one-thousandth the concentration applied. Its rate of elimination from the aqueous humour was approximately $20 \%$ per hour. ${ }^{17}$ From the above it seems that the application of even only one drop of $1 \%$ indomethacin an hour prior to surgery will produce a peak concentration of $8-9 \mu \mathrm{g} / \mathrm{ml}$. This is well within the range of effective inhibition of prostaglandin synthesis by microsomal fractions of the anterior uvea of rabbits. ${ }^{19}{ }^{21}$ In view of the lack of information pertaining to the human eye, we assume that 4 drops of $1 \%$ topical indomethacin applied at half-hourly intervals can effectively suppress prostaglandin production following argon laser trabeculoplasty. We avoided postoperative indomethacin treatment, since it has been found from invitro and in-vivo studies on experimental animals that indomethacin inhibits prostaglandin degradation enzymes and the transport mechanism responsible for the removal of prostaglandins from the eye. ${ }^{21}{ }^{22}$

We would also like to emphasise the advantages of using corrected intraocular pressures ${ }^{9}$ in the assessment of the efficiency of argon laser trabeculoplasty. As compared with the normal eye the glaucomatous eye, with its impaired outflow facility, is known to sustain greater diurnal intraocular pressure fluctuations in response to the diurnal variations in the secretory activity of the ciliary body..$^{23}$ A number of patterns in the diurnal fluctuation of the intraocular pressure of glaucomatous patients are recognised. ${ }^{24}$ This can be a source of bias when measurements of the intraocular pressure are taken at different times of the day. This problem is of importance in our study, in which argon laser trabeculoplasty was performed in the early morning, to enable us to follow up the patients for five hours immediately following the operation. When the patients subsequently returned for follow-up one week and one month after the operation, their intraocular pressures were usually measured in the early afternoon. In order to eliminate the potential bias caused by diurnal variations, we calculated corrected intraocular pressures, comparing the intraocular pressure of the treated eye with that of the untreated eye.
A further reason for using corrected intraocular pressures is to overcome the bias caused by poor compliance of patients. The well known problem of poor compliance of glaucoma patients ${ }^{25}$ is particularly severe in our patients. It is our feeling that many patients who fail to take medications adequately prior to argon laser trabeculoplasty start to comply for at least a short period after treatment. (This is due in part to their realisation of the severity of their condition and their knowledge that argon laser treatment is an alternative to surgery.) In these cases a reduction in intraocular pressure following argon laser trabeculoplasty may be due in part to better compliance with medication and not solely to the laser treatment. The use of corrected intraocular pressures can help to overcome this bias.

We wish to draw attention to the fact that in the present study the person who carried out the argon laser trabeculoplasty (YAG) also measured the intraocular pressures before and after treatment. This is acceptable and does not cause bias, because the aim of the study was not to evaluate the effect of argon laser trabeculoplasty as such but to evaluate the effect of indomethacin or placebo pretreatment on the pressure reduction following argon laser trabeculoplasty. Since this was a double-masked study, a second person (MW) kept the code, and a nursing sister applied the indomethacin or placebo prior to treatment. The person who treated the patients and measured their intraocular pressures (YAG), and the nursing sister who applied the drops, had no way of knowing how each patient was pretreated.

In this randomised, double-masked study we found no significant difference in either the incidence or the magnitude of the mean maximum corrected intraocular pressure increase between the indomethacin-treated group $(1.39 \pm 4.18 \mathrm{mmHg})$ and the placebo-treated group $(1.63 \pm 5.8 \mathrm{mmHg})$ in the immediate postoperative period. However, it took longer for this maximum intraocular pressure increase to develop in the indomethacin-treated group $(2.34$ \pm 1.30 hours) compared with the placebo-treated group (1.54 \pm 0.96 hours). These differences in time were found to be significant $(p<0.01)$. The changes were detected at an earlier time compared with previous studies. ${ }^{911}$ The delay of the indomethacintreated group in attaining the maximum intraocular pressure increase may be due to partial suppression of the inflammation by the indomethacin, leading to a slower development of the intraocular pressure increase. After one week there was no significant difference between the mean corrected pressure values of the two groups, the indomethacin-treated group being $-4.18 \pm 5.09 \mathrm{mmHg}$ and the placebotreated group $-4 \cdot 25 \pm 3.46 \mathrm{mmHg}$.

When calculated for one month, however, the 
corrected falls in mean intraocular pressure were found to be significantly greater for the placebotreated group. The mean corrected intraocular pressure change for the indomethacin-treated group was $-3.65 \pm 3.66 \mathrm{mmHg}$ and that of the placebotreated group $-5 \cdot 59 \pm 2.18 \mathrm{mmHg}(\mathrm{p}<0.01)$.

The above results clearly demonstrate a significantly adverse effect of pretreatment with indomethacin ophthalmic suspension on the intraocular pressure reduction one month after the operation. We therefore conclude that indomethacin ophthalmic suspension should not be used as a pretreatment for argon laser trabeculoplasty.

The authors thank MSD International for supplying the indomethacin ophthalmic suspension and the placebo, Miss Alison Davis for carrying out the statistical analysis, and Dr Joan Kessel for assisting in preparing the manuscript.

\section{References}

1 Wise JB, Witter SL. Argon laser therapy for open angle glaucoma. Arch Ophthalmol 1979; 97: 319-22.

2 Wise JB. Long term control of adult open angle glaucoma by argon laser treatment. Ophthalmology (Rochester) 1981; 88: 197-202.

3 Schwartz AL, Whitten ME, Bleiman B, Martin D. Argon laser trabecular surgery in uncontrolled phakic open angle glaucoma. Ophthalmology (Rochester) 1981; 88: 203-12.

4 Wilensky JT, Jampol LM. Laser therapy for open angle glaucoma. Ophthalmology (Rochester) 1981; 88: 213-7.

5 Thomas JV, Simmons RJ, Belcher CD. Argon laser trabeculoplasty in presurgical glaucoma patients. Ophthalmology (Rochester) 1982; 89: 187-97.

6 Pollack IP, Robin AL. Argon laser trabeculoplasty. Its effect on medical control of open angle glaucoma. Ophthalmic Surg 1982; 13: 637-43.

7 Thomas JV, Simmons RJ, Belcher CD. Complications of argon laser trabeculoplasty. Glaucoma 1982; 4: 50-2.

8 Forbes M, Bansal RK. Argon laser goniophotocoagulation of the trabecular meshwork in open angle glaucoma. Glaucoma $1982 ; 4: 100-7$.
9 Weinreb RN, Ruderman J, Juster R, Zwieg K. Immediate intraocular pressure response to argon laser trabeculoplasty. $\mathrm{Am}$ J Ophthalmol 1983; 95: 279-86.

10 Ruderman JM, Zweig KO, Wilensky JT, Weinreb RN. Effects of corticosteroid pretreatment on argon laser trabcculoplasty. Am J Ophthalmol 1983; 96: 84-9.

11 Rodrigues MM, Spacth GL, Donohoo P. Electron microscopy of argon laser therapy in phakic open angle glaucoma. Ophthalmology (Rochester) 1982; 89: 198-210.

12 Eakins KE. Prostaglandin and non-prostaglandin mediated breakdown of the blood aqueous barricr. Exp Eye Res 1977; (suppl): 483-98.

13 Unger WG, Cole DF, Bass MS. Prostaglandin and neurologically mediated ocular response to laser irradiation of the rabbit iris. Exp Eye Res 1977; 25: 209-20.

14 Eakins KE. Prostaglandins and prostaglandin synthetase inhibitors: actions in ocular disease. In: Robinson HJ, Vane JR, cds. Prostaglandin synthetase inhibitors. New York: Raven Press, 1974: 343-52.

15 Sawa M, Masuda K. Topical indomethacin in soft cataract aspiration. Jpn J Ophthalmol 1976; 20: 514-9.

16 Mochizuki M, Sawa M, Masuda K. Topical indomethacin in intracapsular extraction of senile cataract. Jpn J Ophthalmol $1977 ; 21: 215-26$.

17 Hanna C, Sharp JD. Ocular absorption of indomethacin by the rabbit. Arch Ophthalmol 1972; 88: 196-8.

18 Conquet P, Plazonnet B, Le Douarec JC. Arachidonic acidinduced elevation of intraocular pressure and anti-inflammatory agents. Invest Ophthalmol Vis Sci 1975; 14: 772-5.

19 Bhattacherjee P, Eakins KE. Inhibition of the prostaglandin synthetase systems in ocular tissues by indomethacin. $\mathrm{Br} J$ Pharmacol 1974; 50: 227-30.

20 Bhattacherjee P, Eakins KE. A comparison of the inhibitory activity of compounds on ocular prostaglandin biosynthesis: Invest Ophthalmol Vis Sci 1974; 13: 967-72.

21 Pace-Asciak C, Cole S. Inhibitors of prostaglandin catabolism. 1. Differential sensitivity of 9-PGDH, 13-PGR and 15-PGDH to low concentrations of indomethacin. Experientia 1975; 31: 143-5.

22 Bito LZ. Absorptive transport of prostaglandins from intraocular fluids to blood: a review of recent findings. Exp Eye Res 1973; 16: 299-306.

23 Kolker AE, Hetherington J. Becker-Schaffer's diagnosis and therapy of the glaucomas. 5th ed. St Louis: Mosby, 1983: 112.

24 Duke-Elder S. System of ophthalmology. St Louis: Mosby, 1969; 11: 456-61.

25 Davidson SI, Akingbehin T. Compliance in ophthalmology. Trans Ophthalmol Soc UK 1980; 100: 286-90. 